\title{
O governo da gestação por substituição na era da biotecnologia: as biolegalidades cambiantes do parentesco
}

Governing surrogacy in the age of biotechnology: the shifting biolegalities of parenthood

\author{
Sonja van Wichelen' \\ https://orcid.org/0000-0003-1196-7551 \\ sonja.vanwichelen@sydney.edu.au \\ I University of Sydney - Sydney, Austrália
}




\title{
Resumo
}

Este artigo examina como o direito interage com as mudanças biotecnológicas, olhando para a maneira em que, em processos de reprodução assistida, justificativas legais se relacionam com o conhecimento biológico e social que está redefinindo "pai" e "mãe". Usando o conceito de "biolegalidade", foco no surgimento de novas formas de parentalidade legal, analisando como a reivindicação por direitos pode ser baseada em verdades tanto genéticas quanto jurídicas. Ao contrário dos entendimentos convencionais em que "a lei se arrasta atrás da tecnologia", o artigo visa demonstrar como o conhecimento jurídico interage com as tecnologias e as ciências da vida para rearranjar os próprios entendimentos sobre os direitos. A partir das práticas dos tribunais australianos em relação à legalização da paternidade de crianças nascidas de uma gestação por substituição no exterior, analiso argumentos e decisões de casos federais e locais, demonstrando como uma "abordagem de direitos humanos" promovida por juízes que agem no "melhor interesse de a criança" desestabiliza a aplicação de leis australianas locais que proíbem a gestação por substituição comercial.

Palavras-chave: reprodução global; gestação por substituição; biolegalidade, lei e biotecnologia.

\begin{abstract}
This article examines how law interacts with biotechnological changes and how legal justifications engage with biological and social knowledge that redefine parenthood through assisted reproduction. Using the concept of "biolegality", I conceptualize the emergence of new forms of legal parenthood and analyse how rights-claims are based on both genetic and legal truth. Contrary to conventional understandings that in the pursuit of justice "law lags behind technology," the article demonstrates how legal knowledge interacts with the life sciences and technologies and rearranges understandings of rights. Focusing on Australian court practices that concern the legalization of parenthood for children born out of overseas surrogacy arrangements, I analyse arguments and decisions from federal and local cases and demonstrate how a "human rights approach" promoted by judges that act in the "best interest of the child" destabilizes the enforcement of local Australian law prohibiting commercial surrogacy.
\end{abstract}

Keywords: global reproduction; surrogacy; biolegality; law and biotechnology. 


\section{Introdução}

Em 2013, o caso Mason \& Mason and Anor ${ }^{1}$ foi discutido no Tribunal de Família federal da Austrália. Envolvia um casal gay (A. Mason e B. Mason) que contratou uma mulher na Índia para a gestação de sua prole. Gêmeos nasceram desse acordo em 2011. Um dos pais contratantes era o pai genético, tendo fornecido o esperma para o procedimento de fertilização in vitro. Tratava-se de um arranjo de gestação por substituição em que a mãe de nascimento não era a mãe genética. O procedimento de fertilização in vitro envolveu óvulos de uma doadora indiana anônima. Os filhos, então, são meio indianos geneticamente e, racialmente, diversos de seus futuros pais.

O casal foi à Justiça para obter uma declaração de paternidade para o pai genético dos filhos. Contra julgamentos anteriores (incluindo um que ela mesmo tinha feito), a juíza do caso, Justice Ryan, decidiu contra declarar tal filiação. Entretanto, foram concedidas a ambos os pais pretendidos ordens parentais - acordos legais que transferem a autoridade parental da mulher que cedeu temporariamente seu útero (e seus possíveis parceiros) para os pais pretendidos - para que a criança pudesse viver com eles que, assim, compartilhariam responsabilidades parentais iguais. ${ }^{2} \mathrm{O}$ "interesse prioritário da criança" foi a consideração primordial na concessão dessas responsabilidades parentais.

Essa sentença revela um certo paradoxo entre o que o Estado considera legal e a maneira como os direitos humanos se manifestam. A gestação por substituição é proibida em Nova Gales do Sul - o estado australiano onde esse caso ocorreu e onde os pais de intenção residem. A lei de adoção de 2010 em Nova Gales do Sul criminaliza os acordos comerciais com mulheres propondo disponibilizar seus úteros, independentemente de onde a gestação ocorra, prevendo uma pena de vários anos de prisão. ${ }^{3}$ No entanto, as proibições legais

1 Mason \& Mason and Anor, [2013] FamCA 424.

2 As ordens de paternidade reconhecem alguns arranjos de paternidade, entre os quais aqueles oriundos de acordos de gestação por substituição. Eles estipulam quem são os responsáveis pela tutela da criança.

3 Esse também é o caso para outros dois estados - o Território da Capital Australiana e Queensland. 
não impedem que indivíduos e casais australianos continuem organizando gestações por substituição no exterior. Pelo contrário, conforme estimativas (pelo menos, antes da pandemia global de Covid-19), a prática estava em crescimento. ${ }^{4}$ Devido às dificuldades de adotar uma criança (nacional ou internacionalmente) e/ou encontrar participantes para uma gestação por substituição altruísta na Austrália, os futuros pais procuravam candidatas à gestação para além das fronteiras. ${ }^{5}$

Têm chamado muita atenção os debates morais e éticos sobre as maternidades substitutas comerciais violarem ou não os direitos humanos - especialmente os de mulheres e crianças (Bromfield; Rotabi, 2014; Stark, 2011-2012; Tobin, 2014). Essas discussões tendem a se concentrar na questão de como os estados soberanos devem regular as gestações por substituição comerciais e/ou transnacionais. Nosso caso na Austrália mostra, porém, que nem uma regulamentação rígida restringe necessariamente a prática da gestação por substituição transfronteiriça. Meu objetivo neste artigo é compreender como essa situação aparentemente paradoxal - ou seja, o crescimento da gestação por substituição transfronteiriça apesar de regulamentações claras que proíbem a prática - pode ocorrer. Para tanto, argumento que precisamos nos concentrar, por um lado, na produção de conhecimentos em torno de entendimentos biocientíficos de relacionalidades genéticas e, por outro lado, nos entendimentos legais de parentesco e paternidade. Meu enfoque nas práticas de conhecimento - em vez de bioético ou de direitos humanos propriamente ditos - permite uma análise que inclui várias maneiras pelas quais a bioética ou os direitos humanos estão implicados em estruturas de legitimação.

4 De acordo com a pesquisa conduzida por Surrogacy Austrália, um grupo de advocacy para pais pretendidos, o número de arranjos transnacionais de gestação por substituição na Austrália aumentou de 97 em 2009 para 296 em 2012 (Cohen, 2017). Contudo, quando recentemente a Tailândia e a Índia proibiram a gestação por substituição, esses números diminuíram e, durante a Covid-19, parecem ter caído para zero (Fronek; Rotabi, 2020).

5 Os estados da Austrália permitem somente a gestação por substituição altruística e a mãe substituta tem uma série de direitos legais antes de seu vínculo legal com a criança ser terminado. A Austrália também foi um dos primeiros países do mundo a reconhecer que as pessoas concebidas por doação de esperma ou óvulo têm o direito de conhecer suas origens genéticas. Com o anonimato de doadores sob questão, os estados começaram a reduzir a possibilidade de doação anônima. A adoção, como veremos mais adiante, também seguiu esse mesmo percurso. 
O caso Mason \& Mason and Anor descrito acima é um ponto de partida para a comparação de argumentos e decisões com outros casos federais e estaduais na Austrália. Proponho demonstrar como "a abordagem de direitos humanos" promovida pelos juízes agindo no "melhor interesse da criança" desestabiliza a aplicação da lei australiana estadual a respeito da gestação por substituição comercial. Interessa-me em particular examinar como a lei interage com as mudanças biotecnológicas. Pergunto como as justificações legais mobilizam conhecimentos biológicos e sociais que, por sua vez, constituem uma paisagem cambiante dos direitos e da ética em torno da gestação por substituição. Usando o conceito de "biolegalidade" eu examino a formação de novas reivindicações de direitos emergindo da interseção da lei e da biologia no contexto de desigualdades globais e das políticas de imigração.

A partir dos campos de antropologia legal e de estudos de ciência e tecnologia, investigo as novas sociabilidades que essas interações produzem, mas também as lacunas que criam. Contrariamente a entendimentos convencionais de que "a lei se arrasta atrás da tecnologia", o artigo visa demonstrar como o conhecimento jurídico interage com as tecnologias e as ciências da vida para construir o próprio conceito de direitos. Além disso, a interação das informações, dos fatos e dos conhecimentos, inclui referências fortes ao "discurso da adoção", sugerindo um reenquadramento de tópicos sobre gestação por substituição através da moldura de adoção legal. Discuto finalmente como o uso atual da perspectiva dos direitos humanos com ênfase no interesse prioritário da criança facilita a gestação por substituição transfronteiriça, reforçando desse modo ideias neoliberais de família nuclear. Nesse caso, os direitos são coconstituídos pela lei e pela biologia, desembocando na formação de novas biolegalidades. Porém, essas biolegalidades particulares também fazem parte de uma biopolítica que, por sua vez, facilita determinadas economias reprodutivas.

\section{Entendimentos disputados de vínculos parentais em arranjos internacionais de gestação por substituição}

Turismo para fins reprodutivos não ocorreria na Austrália se as condições legais, econômicas e políticas de outros países não permitissem a prática comercial da gestação por substituição. Em 2015, ano em que foi conduzida esta 
pesquisa, vários estados nos EUA (incluindo Nova York, Califórnia, Arkansas e Nova Hampshire), Índia, Rússia e Ucrânia permitiam determinadas formas de gestação por substituição comercial.

Graças à disponibilidade de sofisticadas facilidades médicas e a fama de prover serviços de excelência na área de tecnologias reprodutivas, a Índia (que, junto com o Reino Unido, foi pioneira na fertilização in vitro) se tornou líder nas tecnologias de gestação por substituição e um destino comum do turismo para fins reprodutivos. Candidatas a mãe contratada indianas eram populares entre casais inférteis no Norte Global por causa de seu custo relativamente baixo. Australianos pretendendo assim constituir uma família pagavam uma fração do que lhes custaria nos EUA. Ao mesmo tempo, as clínicas indianas também se tornavam mais competitivas, não apenas nos preços, mas na contratação de mulheres indianas como gestantes substitutas. A prática também se tornou comum na própria Índia, onde celebridades (como a estrela de Bollywood Shah Rukh Khan) discutiram publicamente os seus usos dos serviços de gestação por substituição.

Na época, a Índia só permitia a substituição gestacional quando a mãe de gestação substituta não era a mãe genética (Smerdon, 2012). O procedimento exigia a doação de óvulos ou de um doador anônimo ou da mãe de intenção. Também envolvia necessariamente a transmissão para a criança do material genético de pelo menos um dos pais de intenção. Dessa forma, a cidadania da criança podia ser solicitada no país do pai genético, o vínculo legal sendo estabelecido com base em um teste de DNA. A Índia não concedia cidadania para as crianças engendradas no país por gestação de substituição.

Após o caso altamente midiatizado da bebê Manji em 2008, houve apelos para estabelecer uma regulamentação mais rigorosa sobre a gestação por substituição na Índia. Tratava-se de uma menina japonesa nascida por um acordo comercial entre um homem japonês (o pai genético), uma mulher indiana que cedia temporariamente seu útero e uma doadora anônima de óvulos. Pelo final de 2009, outro caso, conhecido como o caso dos gêmeos Balaz, aumentou ainda mais a necessidade de regular a gestação por substituição. No caso, a Alemanha (que criminaliza a gestação por substituição comercializada) negou cidadania aos gêmeos apesar de seus pais de intenção (um deles, o pai genético) serem alemães. A Índia tampouco concedeu cidadania já que as crianças não estavam geneticamente relacionadas a um cidadão indiano. Na ausência de clareza, 
a Corte Suprema da Índia teve de intervir por razões humanitárias. ${ }^{6}$ Em agosto de 2016 foi aprovada uma lei que pôs fim a todas as formas comerciais de gestação por substituição na Índia - inclusive os arranjos internacionais.

\section{Cidadania, paternidade e direitos humanos}

Os casos altamente midiatizados envolvendo Austrália, Japão e Alemanha atestam problemas surgidos em países que proíbem a gestação por substituição comercial. Como tais, Austrália, Japão, Alemanha, Dinamarca e França estão cada vez mais confrontados com situações legais em que a criança engendrada por um processo transnacional de gestação por substituição expõe tensões fundamentais entre as políticas públicas do Estado soberano e o que se percebe como o melhor interesse da criança.

Autoridades australianas automaticamente concedem cidadania australiana a crianças geneticamente vinculadas a pais australianos. Assim, ao contrário da Alemanha e do Japão, que não concederam cidadania nos casos do bebê Manji e dos gêmeos Balaz, as crianças encomendadas entrando na Austrália não seriam apátridas. A cidadania australiana, porém, não significa reconhecimento do parentesco legal. A paternidade é estabelecida conforme legislações estaduais e territoriais. Contudo, considerando que a gestação por substituição comercial é ilegal na maioria dos estados, não pode haver reconhecimento automático das crianças assim engendradas no exterior. Esses pais precisam, ao invés, solicitar as "ordens parentais" emitidas pelo Tribunal de Família federal. As ordens parentais atribuem a responsabilidade parental sem estabelecer a paternidade legal. A existência de uma relação parental, aliás, não é um pré-requisito para solicitar ou receber uma ordem parental (Keyes, 2013, p. 35).

6 Em maio de 2010, os gêmeos Balaz receberam documentos de identidade e uma autorização de saída da Índia. As autoridades indianas insistiram que se tratava de um evento extraordinário que não deveria estabelecer um precedente. Da mesma forma, as autoridades alemãs abriram uma única exceção e emitiram vistos para os gêmeos. Em ambos os países, a decisão foi justificada com o argumento de que o caso dos gêmeos seria contemplado pelos acordos de adoção internacional, conforme estabelecido pela Convenção de Adoção de Haia (Smerdon, 2013, p. 206-207). 
Estima-se que centenas de crianças entraram na Austrália como resultado de processos de gestação por substituição realizados no exterior. No entanto, houve apenas 20 casos de ordens parentais (como no caso Mason), o que sugere que a maioria das famílias vive sem a segurança ou proteção da paternidade (ou maternidade) legal ${ }^{7}$ (Keyes, 2013). Em função dos custos legais, do risco de ser acusado de crime, e das parcas chances da receber uma declaração legal de paternidade, muitas pessoas optam por não buscar reconhecimento formal. Em alguns casos, o pai genético consta na certidão de nascimento emitida pelo país em que seu filho nasceu. É possível que essa certidão seja aceita por algumas instituições na Austrália. Entretanto, considerando que, conforme a lei australiana, nem o pai genético nem seu companheiro pode ser oficialmente reconhecido como pai, a unidade familiar poderá enfrentar dificuldades no futuro.

Como o que poderíamos chamar de "perspectiva dos direitos humanos" se enquadra em casos de gestação por substituição dentro e além de fronteiras internacionais? Em um caso anterior ao dos Masons (Ellison and Anor \& Karnchanit, de 2012), a juíza Ryan tinha convidado a Comissão Australiana de Direitos Humanos a se pronunciar. Para além das considerações quanto ao sistema legal internacional, à mãe de nascimento, e à natureza do relacionamento da criança com os pretendentes, a posição dos direitos humanos no caso australiano foi em última análise modelada pelo princípio "do melhor interesse da criança". Este foi interpretado como o direito legal de a criança ter direitos e de ser protegida - o que somente poderia ser garantido com a cidadania e o reconhecimento do status legal de sua filiação dos pais australianos. É do interesse da criança ter pais e, por isso, os pais que infringiram a lei doméstica para ter seus filhos são punidos apenas de forma limitada e burocrática. Isso explica por que, apesar de essa ilegalidade explícita ser praticada em vários estados, não houve nenhuma condenação. Notamos aqui uma lacuna que pode emergir entre a lei e a ética, como nos casos de abrangência global que precisam ser julgados localmente.

7 No caso Mason, como em outros casos relativos à gestação por substituição, nenhum - ou apenas um - dos pais é reconhecido como pai ou mãe legal da criança, lembrando o "parentesco manco" que caracteriza a relação precária entre certos pais e filhos depois de uma separação, divórcio ou morte na família - ver Millbank (2011) e Hague Conference on Private International Law (2012). 
Uma posição similar se encontra na Corte Europeia de Direitos Humanos, que deliberou, nos primeiros anos da gestação por substituição, contra as decisões nacionais de não concessão de cidadania às crianças nascidas de acordos comerciais transfronteiriços envolvendo gestação por substituição. ${ }^{8}$ Baseados no artigo 8 da Declaração Europeia de Direitos Humanos, que é o direito a respeito da vida privada e familiar, os ministros decidiram que os pais de intenção que podem comprovar um vínculo biológico com o filho devem ser reconhecidos como pais legais (Van Beers, 2014). Tais intervenções revelam uma posição pragmática em relação à prática da gestação por substituição comercial transnacional. A Austrália parece representar um microcosmo do que acontece em escala regional na Europa.

A tensão entre a posição do estado australiano sobre a gestação por substituição e o que poderia ser visto como "o melhor interesse da criança" é bem ilustrada pela mudança de posição da juíza Ryan entre um caso e outro. No caso Mason posterior, ao invés de aplicar as disposições gerais de paternidade que constam na jurisdição do tribunal federal, ela argumentou que, para determinar a filiação em casos de gestação por substituição, deveriam ser aplicadas as disposições legislativas de 2010 sobre adoções - leis que se remetem à jurisdição da lei estadual. ${ }^{9}$

Referindo-se à Lei da Família, a juíza Ryan concluiu que não seria possível conceder uma declaração oficial de parentalidade nos casos envolvendo arranjos de gestação por substituição, fora da lei estadual. Sua decisão vem ao encontro de outros casos recentes. Em vez de conceder declarações de paternidade, são concedidas ordens parentais, limitadas a uma atribuição de responsabilidade parental até que a criança alcance 18 anos. Indica-se dessa maneira um movimento em direção coerente com os regulamentos estaduais que proíbem a prática. Além disso, já houve vários casos encaminhados pelo juiz para a Promotoria Pública em função da ação ilegal dos demandantes. Acredita-se que tudo isso tenha levado a uma diminuição de pedidos de declaração de filiação legal (ver Millbank, 2011).

8 Ver Mennesson and Others v. France (no. 65192/11) e Labassee v. France (no. 65941/11).

9 Como a juíza Ryan argumentou: "Não obstante minha decisão em Ellison and Anor \& Karnchanit, agora tenho reservas quanto à aplicação das presunções parentais gerais em relação a crianças nascidas por meio de um acordo de gestação por substituição" (Mason \& Mason and Anor, p. 2). Ver também Ellison and Anor \& Karnchanit, [2012] FamCA 602. 
Outra consideração-chave no caso posterior foi o nível de exploração da gestação por substituição. Foi apresentado à juíza um contrato que, entre outros detalhes, indicava uma transferência de cerca de 5.000 dólares australianos em troca da concessão temporária de útero pela mulher indiana. A juíza Ryan estava especialmente preocupada com dois aspectos do contrato. $\mathrm{O}$ primeiro dizia respeito às cláusulas que limitavam a capacidade da mãe biológica de cuidar de sua saúde durante a gravidez ou de tomar decisões sobre o parto. O segundo problema era que o contrato estava em inglês, assinado pela mãe biológica apenas com uma impressão digital, dando para entender que a gestante contratada era analfabeta em inglês. Por insistência do tribunal, um termo de consentimento foi oferecido e assinado pela mãe biológica através de um tabelião público na Índia. A mãe biológica assim reconheceu o conteúdo do contrato original e deu consentimento ao pedido de parentalidade do casal. As declarações juramentadas forneceram as evidências necessárias de que a mulher não tinha sido coagida e tinha compreendido integralmente os termos do contrato.

Vemos como os entendimentos em torno dos direitos da criança, cidadania e paternidade têm sido desafiados pelas novas tecnologias reprodutivas. Surge então a questão: se o conhecimento jurídico sobre a gestação por substituição é escasso, em quais outros conhecimentos a jurisprudência se baseia para fundamentar suas perspectivas e decisões?

\section{Emaranhados com os conhecimentos sobre a adoção}

No caso dos Masons, a juíza Ryan nomeou um advogado, independente e especializado, para representar os interesses das crianças. Ela também encomendou um relatório para descrever a situação familiar do requerente com seu parceiro e os filhos. Além de confirmar a aptidão do casal para a criação dos gêmeos, o conselheiro familiar levantou uma série de questões quanto ao futuro bem-estar das crianças e a maneira como os pais poderiam enfrentar certos desafios. Uma questão dizia respeito ao que o conselheiro denominava "questões culturais", surgidas do fato de as crianças serem geneticamente meio indianas. Conforme o conselheiro, entre outras medidas protetoras que os pais estavam tomando constava seu desejo explícito de viver na proximidade de 
famílias com uma composição étnica semelhante à de sua família. O conselheiro também sugeriu que as crianças poderiam se beneficiar da convivência, ainda na Austrália, entre famílias indianas onde, por exemplo, poderiam participar de festivais e celebrações indianas:

Tomada de empréstimo ao discurso da adoção, os gêmeos podem enfrentar uma tarefa mais complicada, de fazer sentido de seu lugar no mundo, porque cresceram em uma família em que os rostos dos pais não parecem com os seus - e sem convivência com sua "mãe" ou a cultura dela. Pode haver ocasiões na vida [das crianças] em que elas estarão preocupadas com essa situação. Elas poderão vir a buscar contato com suas mães em momentos significativos de transição, ao longo dos ciclos da vida. Também é possível que [isso] jamais venha a ser um problema para os gêmeos. (Mason \& Mason and Anor, p. 17, grifo meu).

Além disso, o conselheiro familiar argumentou:

Outro argumento apresentado no discurso da parentalidade é que a identidade genética de uma criança faz parte de sua história. Pode haver vantagens médicas para os filhos que conhecem sua ascendência. A mãe doadora e [a mãe de nascimento] e suas famílias estarão, aparentemente, menos inclinadas e/ou sem condições para procurar [os filhos]. Pode haver questões significativas de classe separando as famílias que se tornam evidentes à medida que as crianças exploram suas raízes indianas. Os gêmeos podem notar que suas mães e quaisquer meios-irmãos terão vivenciado trajetórias muito diferentes das suas. Novamente, esse é um problema com qual os pais podem ajudar os filhos a lidar.

Esses exemplos ilustram como a lei acomoda as novas tecnologias. Como observaram os estudiosos de ciência e tecnologia, "o que se sabe na ciência depende significativamente de escolhas anteriores ou simultâneas sobre como se escolhe saber" (Jasanoff, 2007; Latour, 1993). Por ter a capacidade de construir, bem como de reforçar noções prevalentes de expertise e evidência, "os espaços jurídicos operam simultaneamente como espaços epistêmicos" (Jasanoff, 2007). As biotecnologias reorganizam o conhecimento de parentesco euro-americano e os entendimentos gerais sobre relatedness (Dolgin, 1997; Franklin, 2002; Strathern, 2005; Thompson, 2005). Isso inclui a diluição de fronteiras entre a 
compreensão biológica e social ou jurídica do parentesco. Em nosso exemplo, onde o conselheiro familiar se refere ao discurso da adoção, pode-se ver como o conhecimento sobre a adoção se torna uma espécie de matriz para refletir sobre o futuro bem-estar das crianças engendradas pela gestação por substituição.

A analogia com a adoção se mostrou útil na avaliação do tribunal quanto à vida futura das crianças. Mas também pode ser evocada para interpretar as motivações das pessoas que optam pela gestação por substituição para criar uma família. Por exemplo, uma razão importante para as pessoas recorrerem à adoção internacional é pela adoção doméstica não ter sido uma opção viável. ${ }^{10}$ Isso pode se dar por diversos motivos. Em países como a Austrália, encoraja-se o acolhimento familiar de longa duração no lugar da adoção. Além disso, em países onde a adoção doméstica ainda está disponível, um movimento em direção a "adoções abertas", onde os pais de nascimento mantêm algum tipo de contato com seus filhos, tem sido promovido com vigor (Yngvesson, 2010). ${ }^{11}$ Trata-se de um movimento coerente com as políticas - frequentemente nos mesmos países - para restringir o anonimato de doadoras e doadores de óvulos e sêmen. Essas orientações baseiam-se no direito da criança a conhecer seus pais genéticos e biológicos ou de nascimento, assim como o direito às informações médicas que fazem parte de seu direito à saúde. Informações abertas como em práticas não anônimas de reprodução assistida - não são uma prática comum nas arenas transnacionais de adoção ou de gestação por substituição. Ir para além-mar, então, faz duas coisas simultaneamente: primeiro, dribla as leis e regulamentações domésticas sobre reprodução - as que dizem respeito à adoção, às tecnologias de reprodução assistida e à gestação por substituição -; segundo, dá aos futuros pais a possibilidade de ter seus próprios filhos.

A ideia de "sua própria criança" foi muito discutida na literatura sobre parentesco, propriedade e lei (Dolgin, 1997; Melhuus, 2012; Strathern, 2005).

10 A adoção doméstica é rara na Austrália. Desde a "Geração Roubada" da história colonial, em que centenas de milhares de crianças aborígines foram removidas de suas famílias e colocadas em famílias brancas, a Austrália prefere um sistema de colocação familiar de acordo com os princípios da cultura local, com ênfase na preservação da família. Nos últimos anos, por várias razões, o número de crianças disponíveis para adoção internacional diminuiu significativamente. Isso fornece uma outra explicação possível para a razão por que pessoas solteiras e casais gays se voltam para a gestação por substituição no exterior.

11 Ver, por exemplo, Wright et al. (2021) para um relato da adoção aberta na Austrália. 
O ponto importante a ser evidenciado aqui é que ter o "seu próprio filho" não pressupõe necessariamente um desejo biogenético. Refere-se antes ao desejo dos pais pretendentes de ter um relacionamento exclusivo. Essa relação exclusiva também está ancorada na lei, onde a paternidade múltipla não é uma opção (uma vez que a lei permite apenas dois pais). ${ }^{12}$ Consequentemente, novas tecnologias reprodutivas trazem novas situações para o domínio legal em que as definições biológicas, sociais e legais de parentesco estão sendo desafiadas e reconfiguradas.

\section{Biologia na construção das legalidades}

A introdução dos testes de DNA e o conhecimento que decorre dessas tecnologias desafiaram os fundamentos do direito da família (Dolgin, 1997; Strathern, 2005). Contrariamente à opinião de alguns observadores, no entanto, minha análise da jurisprudência contemporânea sobre a gestação por substituição transnacional sugere que a biotecnologia não altera radicalmente nem desafia de todo a compreensão instrumentalista do direito enquanto meio para alcançar determinado fim. Ao introduzir a ideia de certeza, abre, contudo, novas formas de "saber".

Conforme Pottage (2007, p. 324), o que a "verdade" científica fez foi "afrouxar a consistência ontológica do criado [grown] [e] revelar o sentido em que o criado [grown] é produzido e estabilizado por normas e instituições legais". O caso Mason ilustrou a coexistência do sistema jurídico baseado em evidências e a introdução de fatos científicos. A decisão da juíza Ryan de não conceder automaticamente uma declaração de parentesco ao pai geneticamente relacionado atesta a visão de que a lei não se restringe a replicar verdades científicas, mas ela considera como a ordem social se encaixa com o conhecimento científico. Como Jasanoff (2006, p. 335) explica neste contexto:

A verdade social sobre o que constitui uma família e o que significa uma decisão justa aos olhos da Lei opera, nesses casos, independentemente das verdades

12 Para uma análise interessante das gramáticas de parentesco em torno da gestação por substituição na Suécia, consultar a discussão de Payne (2018) sobre formas multilineares de parentesco. 
científicas relativas à reprodução humana ou à identidade genética. Pode-se considerar tais divergências entre a ciência da impressão digital do DNA e a Lei como arbitrárias, e até mesmo injustas, mas é importante reconhecer que elas estão enraizadas em lógicas institucionais que não são e não precisam ser as mesmas. Necessariamente, então, não haverá qualquer correspondência mecânica entre verdades científicas e as evidências legais baseadas na ciência.

Isso não significa que a juíza Ryan tenha rejeitado o conhecimento científico em favor da ordem social. Para estabelecer a cidadania australiana das crianças, um teste de DNA foi encomendado pelo tribunal atestando do fato do requerente ser, mesmo, o pai genético das crianças. Após o estabelecimento desse fato, apurado por um cientista, ele foi admitido no tribunal como prova. A relação genética, no entanto, não é suficiente para que as legislações federal e estadual na Austrália reconheçam o progenitor como um pai legal. Outros fatores, tais como o relacionamento construído com a criança (vida em família) ou como as intenções motivadoras da gestação por substituição, são frequentemente considerados. O papel dos tribunais na regulação das "evidências" sociais e científicas permite que a instituição jurídica agregue tanto a lógica das evidências quanto a verdade científica:

O conhecimento produzido pelos testes (do DNA) fornece uma maneira moderna (a identificação genética) de ter certeza quanto a uma categoria tradicional de parentalidade (a paternidade biológica) - mas é também uma maneira tradicional (estabelecendo a conexão biológica) de definir um tipo completamente moderno de parentalidade (a paternidade cientificamente determinada). (Strathern apud Pottage, 2007, p. 337).

Podemos observar a mistura de parentesco científico e tradicional em outro caso - o caso Blake \& Anor ${ }^{13}$ do Tribunal de Família da Austrália Ocidental onde um pai pretendido mas não geneticamente relacionado com as crianças entrou com um pedido de adoção valendo-se da legislação de adoção naquele estado (Harland; Limon, 2015, p. 160). A juíza Crisford decidiu que o

13 Blake \& Anor, [2013] FCWA 1. 
pretendente poderia adotar as crianças após ter estabelecido que seu parceiro era o pai genético e assim um "pai de nascimento" (progenitor) das crianças. A situação revela uma compreensão de parentalidade expandida, que sugere uma abertura legal para a parentalidade não genética, bem como a reconfiguração da centralidade da "mãe de nascimento" para incluir os progenitores masculinos. Também parece seguir a percepção dominante de que a lei chega frequentemente depois da mudança tecnológica e social (Jasanoff, 2007, p. 768). Como a juíza Crisford afirma:

Sugerir que [o pretendente] é qualquer outra coisa que um pai dentro de seu significado ordinário seria dar as costas para a realidade da família na sociedade contemporânea. (Harland; Limon, 2015, p. 160).

De acordo com Jasanoff, a retórica da justificação legal como principalmente retrospectiva oferece uma possível explicação para a ideia de que a lei chega frequentemente depois da ciência e da mudança tecnológica. No caso em pauta, a alusão da juíza Crisford à "realidade" de "família" na sociedade atual pode ser vista como uma posição arriscada nas rotinas convencionais da prática judicial. A abertura da juíza para uma interpretação mais solta da lei corre o risco de dar a impressão que está fazendo a lei ao invés de aplicá-la - uma prática desencorajada no ramo jurídico. Entretanto, a maneira como interpreta a lei não a transforma necessariamente - nem traz novos arranjos. Ao invés disso, estabelecer o pai genético como pai de nascimento rearranja noções legais de maternidade e paternidade desde e através de conhecimentos legais - mais do que através da própria verdade científica.

Estes rearranjos revelam a tensão que as tecnologias reprodutivas trazem às instituições legais da paternidade e da maternidade. Por um lado, a jurisprudência sobre paternidade foi primeiramente baseada na presunção do fato biológico (também conhecido como a regra pater est). No centro da instituição da lei de família está "uma ficção sustentada por evidências mais do que pelo conhecimento dos fatos em si" (Jasanoff, 2006, p. 336). Para transformar-se em pai legal de uma criança, um homem necessita ser casado, estar de fato em um relacionamento com seu parceiro ou reconhecer legalmente a criança como sua - ou seja, não tem que fornecer uma prova científica. Por outro lado, a maternidade foi por séculos predicada no ato de dar à luz - fato compreendido 
como prova conclusiva (também conhecida como a regra mater semper certa est) (Storow, 2012, p. 593). O exemplo de Blake mostrou uma situação em que a maternidade é transferida ao pai genético. Isso não teria sido possível, porém, se a mulher que emprestou seu útero fosse casada e a regra do pater est valesse na Índia: nesse caso o parceiro dela seria o pai legal.

A relação biológica não se sobrepõe necessariamente aos laços sociais e afetivos das relações familiares. Entretanto, comparar a gestação por substituição com a adoção revela diferentes normatividades em concorrência na interpretação do "melhor interesse da criança" ou do "direito à vida familiar". Tal constatação nos traz a um ponto fundamental na consideração de mudanças provocadas no conhecimento legal pela verdade científica: a produção de novas biolegalidades.

\section{Biolegalidade como biopolítica}

A verdade científica não está livre de moralidade; tampouco a lei se limita a aplicar tecnologias científicas para a produção de conclusões lógicas. As decisões em relação à paternidade influenciam a construção de famílias legítimas e ilegítimas - a lei pode assim ser considerada como um contrato social (ver Franklin, 2019). Por exemplo, que o conhecimento científico produzido pelo teste de DNA seja usado ou não para conceder a declaração de paternidade, o fato de o teste poder ser solicitado, ou tornado compulsório, significa que a paternidade genética já está implícita nos relacionamentos. Contra a ideia de que a lei segue as mudanças sociais - nesse caso, a de constituir uma família através de gestação por substituição - o direito de família é uma agência ativa na produção de costumes sociais e geração de novas famílias. Em suas consequências, as biotecnologias e a geneticização da vida familiar podem, portanto, ser chamadas de "bioconstitucionais" (Jasanoff, 2011, p. 3):

Deslocamentos radicais da representação biológica da vida envolvem amplos reordenamentos na maneira como imaginamos as funções estatais voltadas para a preservação e aprimoramento da vida. Trata-se, de fato, de um reposicionamento de corpos e autopercepções com respeito ao aparato legal, político e moral do Estado. (Jasanoff, 2011, p. 4). 
Não é apenas a biotecnologia, então, que está rearticulando a vida familiar através da lei. Contrariamente à opinião da lei representar as relações sociais, ela também produz novas sociabilidades. O que acontece em casos de gestação por substituição é que os entendimentos sociais heteronormativos de família nuclear estão sendo reconfigurados. A maneira como estão sendo reconfigurados, porém, sinaliza uma reinstitucionalização da família nuclear. Isso foi mais evidente no exemplo de Blake, onde a categoria legal de maternidade era transferida ao pai genético de modo que a etapa da adoção pudesse ser realizada pelo parceiro. Práticas legais envolvendo a gestação por substituição mostram como as doutrinas do direito de família constroem novas formações nucleares da vida familiar ao mesmo tempo que excluem possibilidades de parentalidade múltipla (Smolin, 2015; Tobin, 2014). É possível argumentar que essas novas configurações produzem novas biolegalidades (a biolegalidade da gestação por substituição) e novos corpos biolegais (as subjetividades corporais formadas por tais biolegalidades).

Essas novas formações nucleares da vida familiar cabem bem nos desejos reprodutivos que informam a economia reprodutiva. Os mercados reprodutivos só podem emergir e existir dentro de certas formações de legitimidade que são imbuídas tanto de razão quanto de afeto. A normalização de tecnologias reprodutivas desempenha um papel importante no fortalecimento do que foi chamado de "neoliberalização generalizada da família" (Eng, 2003; Koshy, 2013). Cultivando o desejo reprodutivo, ela contribui para o estabelecimento de uma forma neoliberal de cidadania familiar, em que os indivíduos sentem cada vez mais que não são cidadãos plenos sem a experiência e o consumo da vida familiar (gravidez, nascimento e paternidade). Além disso, a crescente aceitação global de novas tecnologias biomédicas tornou possível a troca transnacional de gametas, embriões e bebês.

As tecnologias transnacionais de reprodução assistida cumprem uma demanda crescente para serviços reprodutivos nas situações em que as viabilidades domésticas estão fora do alcance legal ou financeiro das pessoas. Como diversos investigadores têm demonstrado, os mercados reprodutivos que resultam dessa demanda são altamente estratificados, baseados em desigualdades globais e formados em mecanismos assimétricos de oferta e demanda (Almeling, 2007; Vora, 2009; Waldby; Cooper, 2008). No caso de gestação por substituição, a prática emerge nos países onde grandes parcelas da população 
passam por dificuldades econômicas, aceitando assim fornecer serviços a baixo preço. ${ }^{14}$ Enquanto a prática da gestação por substituição comercial globalizada, racializada e generificada fomenta essas demandas neoliberais por cidadania familiar, o trânsito através das fronteiras reposiciona participantes nos circuitos transnacionais de troca (Hewitson, 2014; Vora, 2009). A integração legal de uma racionalidade econômica em casos de gestação por substituição permite, então, a expansão desse pensamento econômico dentro do pensamento legal. Como Jasanoff (2001, p. 46) afirma ao elaborar uma analogia entre empreendedores americanos inventando biotecnologia, acadêmicos realizando pesquisas biomédicas e pais de intenção recorrendo à gestação por substituição:

A biotecnologia emerge assim como um desabrochar da criatividade humana, possibilitando a expansão desenfreada da fronteira econômica dos Estados Unidos. Com seus significados fundamentalmente modelados pelo pensamento e discurso legais, a manipulação genética se torna um dispositivo para inscrever o excepcionalismo americano na própria cara da natureza.

Tal como mostrado pela solicitação da corte no caso estudado acima, o "consentimento informado" - baseado em uma concepção individualista do sujeito liberal autônomo - se apresenta como teste decisivo para permitir ou negar uma prática controvertida. A mulher contratada pode então ser considerada como um agente econômico racional capaz de tomar decisões informadas. Não existe nenhuma reflexão, contudo, sobre a possível comodificação da gestação. Não se pergunta se a comercialização dessa prática, por si só, pode ser vista como "uma intrusão na condição do ser humano" (Jasanoff, 2001, p. 46). Estas são todas preocupações fundamentais discutidas na lei pública internacional, a saber, a Convenção dos Direitos da Criança, em particular no artigo 35 sobre

14 É importante observar que isso é especialmente pertinente nos casos de gestação por substituição entre pais pretendidos do Norte Global (incluindo Austrália) e mulheres contratadas no Sul Global. A gestação por substituição doméstica e altruísta funciona de maneira diferente. Ver, por exemplo, Jadva, Gamble e Prosser (2021) e Horsey (2016) para o contexto do Reino Unido e Jacobson (2016) e Berend (2016) para o contexto dos EUA. Também existem regras específicas para a gestação por substituição transnacional nos Estados Unidos (ver Smietana, 2018) e na Rússia (Smietana; Rudrappa; Weis, 2021). 
a venda de crianças, e a Convenção sobre a Eliminação de Todas as Formas de Discriminação Contra Mulheres, particularmente com respeito à gravidez e aos direitos reprodutivos (Stark, 2011-2012; Tobin, 2014). Não se trata de argumentar desde uma posição anticomodificação contra a gestação por substituição. A pesquisa etnográfica já mostrou a complexidade desses processos e como a matéria, o valor e o trabalho (biológicos) podem viajar para dentro e para fora das tramas de comodificação (Hoeyer, 2007; Kopytoff, 1986; Rudrappa, 2015). A confiança no "consentimento informado" para a prática da gestação por substituição, porém, demonstra um desrespeito completo por contextos sociais, políticos e jurídicos mais amplos.

No caso australiano da gestação por substituição, embora sem corresponder ao resultado que os solicitantes (ou mesmo os juízes) imaginavam, a concessão de ordens parentais ao invés de uma declaração de paternidade não tem desencorajado os trânsitos transnacionais. Tem caído o número de solicitações para o reconhecimento legal de paternidade. Porém, isso não significa necessariamente que tenham diminuído as viagens transfronteiriças de pessoas procurando realizar uma gestação por substituição. O que significa é que formas extralegais de vida familiar continuarão a aumentar - uma situação que já ocorre devido à expansão da vida familiar para além do modelo heteronormativo. Além disso, como ninguém foi processado nesses casos, as decisões legais se conformam apenas parcialmente à política pública contrária aos processos transnacionais de gestação por substituição comercial.

Proponho aqui que a prática legal de, em nome do melhor interesse da criança, conceder responsabilidades parentais e não processar os futuros pais acaba criando um amálgama entre o estreito "melhor interesse" que privilegia a família nuclear privada, por um lado, e uma abordagem mais ampla de "direitos humanos" que leva em conta o poder e a cultura, por outro. A mesma tendência aparece na Europa. A abordagem pragmática da Corte Europeia de Direitos Humanos foi interpretada como um argumento a favor da tolerância em contraste com a legislação nacional restritiva - mas também revela até onde a perspectiva de direitos humanos contribui para a facilitação da prática do turismo reprodutivo transfronteiriço (Storow, 2012; Van Beers, 2014).

Enquanto juízes lidam com circunstâncias legais no domínio doméstico, surgem demandas por soluções transnacionais. A Conferência de Haia de Direito Internacional Privado foi identificada como a instituição apropriada 
para desenvolver uma regulamentação legal dos arranjos transnacionais de gestação por substituição. Essa instituição também foi responsável pela convenção sobre adoção internacional de 1993. Alguém poderia argumentar - como alguns estudiosos já o fizeram - que enquanto protegia crianças contra o tráfico e a comercialização delas, a Convenção de Adoção de Haia também permitiu uma expansão e normalização do mercado de adoção global (Bhabha, 2004; Smolin, 2006; Van Wichelen, 2019). Na melhor das hipóteses, a Convenção de Adoção de Haia permite mais transparência no processo de adoção internacional. No entanto, como argumenta a jurista Margaret Radin (2016, p. 339), "os mercados exigem a viabilização de regimes favoráveis". A Convenção de Adoção de Haia constitui o regime jurídico que estabelece as regras e práticas para o funcionamento dos mercados de adoção assim como para a criação de novos mercados. O que a convenção faz, em última análise, é representar o "melhor interesse da criança" de uma perspectiva "de direitos humanos" que privilegia uma determinada economia moral da vida familiar. Tal economia moral se vincula às economias capitalistas e à família nuclear (neo)liberal implicada em tais economias.

No que diz respeito à instrumentalização global dos direitos humanos, conforme entendidos pelas doutrinas do "melhor interesse da criança" e do "direito à vida familiar", sugiro que a regulamentação transnacional da gestação por substituição pode estar indiretamente reconfigurando os direitos humanos de forma a encorajar forças de mercado. ${ }^{15} \mathrm{~A}$ reprodução dos direitos humanos, em tal contexto, pode ser vista como sendo constitutiva do neoliberalismo.

As tentativas dos tribunais de fazer o que pensam estar no melhor interesse da criança são sem dúvida nobres e necessárias, e há coisas na vida muito menos nobres que são constitutivas do neoliberalismo. No entanto, pode valer a pena dar um passo atrás para indagar o que aconteceria se as leis contra a gestação por substituição comercial fossem cumpridas pelos tribunais e juízes em vez de serem anuladas por um princípio do "melhor interesse de a criança". O que se vê à primeira vista é o risco de quem busca construir sua família assim, que passaria a ser criminalizado. Mas há também o risco para os bebês que resultam da gestação por substituição, que passariam a permanecer apátridas.

15 Para um argumento semelhante no domínio do comércio e dos direitos humanos, ver Orford (2006) e Erni (2009). 
Subjacente às duas circunstâncias está uma lógica frequentemente naturalizada, pouco comentada, mas que é central na produção de legalidades em torno da gestação por substituição - a da relacionalidade genética. No entanto, como a criança também carrega material genético de outra pessoa - geralmente de uma doadora anônima de óvulos - o "vínculo intencional" é acrescido à justificativa. É a ligação genética (verdade biológica) combinada com a intencionalidade parental (verdade legal) que finalmente informa as justificações do "melhor interesse da criança". Essas negociações parecem refletir como os euro-americanos estão redesenhando fronteiras entre parentesco e comércio, ou entre pessoas e coisas (Strathern, 2005). No contexto do parentesco, o neoliberalismo tem gerado uma economização de relações de parentesco encontrada em instâncias comercializadas e comodificadas de reprodução como na adoção, na reprodução assistida e na gestação por substituição (Kopytoff, 2004). Quanto mais os regimes jurídicos permitem essas formas de economização, mais poderíamos perguntar se as sensibilidades éticas modernas que se opuseram à economização da vida também não estarão mudando.

\section{Conclusão}

As ligações entre direito, ciência e parentesco têm sido pouco examinadas, mas é nessa relação que podem ser melhor estudados os efeitos complexos que biotecnologias têm na formação de instituições jurídicas (Pottage, 2007, p. 340). Este artigo examinou como a globalização acrescenta ainda outra camada de complexidade a essa dinâmica. Ao explorar a maneira como as solicitações de declaração de paternidade são justificadas em casos de gestação por substituição transnacional, meu objetivo foi investigar como dois sistemas ontológicos de verdade (lei e ciência) puderam cooperar, reinstaurar, alterar ou ofuscar um conhecimento do parentesco. A comparação entre a gestação por substituição e a adoção internacional revelou dimensões normativas da relação entre lei e ciência, mas também realçou como esta normatividade não está necessariamente ligada a uma preferência por um desses sistemas de verdade sobre o outro.

No que toca à gestação por substituição, a lei parece ter simultaneamente enormes poderes simbólicos e imensa limitação prática. Quando a gestação por substituição transnacional foi banida em diversos estados australianos, 
isso não impediu as pessoas de cruzarem fronteiras em busca de facilidades em outros territórios. Na complexidade global de fluxos tecnológicos, de gametas e bebês, o direito parece inevitavelmente paroquial. Mas, contrariamente à compreensão convencional de que a lei chega depois de ciência e tecnologia e de que a lei precisa se pôr em dia com o fluxo global de tecnologias reprodutivas, os casos discutidos neste artigo sugerem outra visão. As técnicas biológicas podem estar esticando os limites da doutrina legal, mas é o conhecimento legal que está reconfigurando o conhecimento social. Demonstrei isso através da discussão sobre parentalidade e a integração do conhecimento da adoção em justificações acerca das práticas da gestação por substituição. Isso é epistemologicamente feito por meio da lei. Além disso, ao contrário da crença de que o direito promove um entendimento heteronormativo da família nuclear, a prática jurídica relativa à gestação por substituição mostra como favorece novas formações da família nuclear, ao mesmo tempo que exclui formas de paternidade múltipla.

Por fim, a intervenção de um entendimento específico dos direitos humanos, conduzido pelas doutrinas do "melhor interesse da criança" e do "direito à vida familiar", parece facilitar ao invés de limitar práticas transnacionais comerciais de gestação por substituição. A questão impertinente que se coloca é se a formulação de uma lei internacional - como a Convenção de Haia sobre a gestação por substituição transnacional - é capaz de conter o abuso, a exploração e o tráfico. A preocupação que este artigo buscou demonstrar é como tal regulação transnacional também pode apresentar o risco de sustentar e manter um mercado global de gestação por substituição. Isso ocorre porque histórias complexas de desigualdade, oportunidade econômica e disponibilidade de tecnologias médicas continuam a moldar diferentes situações globais em que (alguns) indivíduos cruzam fronteiras para ter acesso a uma gestação por substituição comercial enquanto (alguns) outros estão tendo que fornecer esse serviço. Nesse espaço, além de considerar a reivindicação de certos indivíduos mais ricos por seus direitos reprodutivos, é necessário perguntar quais as implicações desses direitos para os participantes mais vulneráveis das interações. Esses participantes vulneráveis - já sem espaços protetivos em suas respectivas regiões - seriam pouco visíveis nas tentativas transnacionais de regular a prática. Aqui, os efeitos intencionais e não intencionais em torno da interação dos mercados, da lei e da moralidade geralmente atuam 
em benefício dos futuros pais. O que necessitamos, então, não é tanto uma chamada para mais regulação transnacional (como nós a conhecemos), mas chamadas para uma discussão aprofundada em torno de instrumentos (legais e não legais) novos de proteção - uma discussão que vai além do paradigma bioético do consentimento informado. Além disso, esses novos instrumentos de proteção precisariam acompanhar as mudanças nos entendimentos biolegais da parentalidade - aqueles formados por práticas de conhecimento biogenético e jurídico dentro, mas também fora, dos tribunais. Essas questões já estão sendo discutidas em algumas arenas domésticas; cabe agora levá-las para a arena global.

Traduzido do inglês por Ethon da Fonseca

\section{Referências}

ALMELING, R. Selling genes, selling gender: egg agencies, sperm banks, and the medical market in genetic material. American Sociological Review, [s. l.], v. 72, n. 3, p. 319-340, 2007.

BEREND, Z. The online world of surrogacy. New York: Berghahn Books, 2016.

BHABHA, J. Moving babies: globalization, markets and transnational adoption. The Fletcher Forum of World Affairs, [s. l.], v. 28, n. 2, p. 181-197, 2004.

BROMFIELD, N. F.; ROTABI, K. S. Global surrogacy, exploitation, human rights and international private law: a pragmatic stance and policy recommendations. Global Social Welfare, [s. l.], v. 1, n. 3, p. 123-135, 2014.

COHEN, H. Surrogacy booming in Australia despite legal issues. ABC News, [s. l.], 9 Feb. 2017. Disponível em: https://www.abc.net.au/news/2017-02-10/surrogacy-booming-in-australia-despite-legal-issues/8255966. Acesso em: 15 nov. 2020.

DOLGIN, J. Defining the family: law, reproduction, and technology in an uneasy age. New York: New York University Press, 1997.

ENG, D. L. Transnational adoption and queer diasporas. Social Text, [s. l.], v. 21, n. 3, p. 1-37, 2003.

ERNI, J. Human rights in the neo-liberal imagination. Cultural Studies, [s. l.], v. 23, n. 3, p. 417-436, 2009. 
FRANKLIN, S. Embodied progress: a cultural account of assisted conception. London: Routledge, 2002.

FRANKLIN, S. Developmental landmarks and the warnock report: a sociological account of biological translation. Comparative Studies in Society and History, [s. l.], v. 61, n. 4, p. 743-773, 2019.

FRONEK, P.; ROTABI, K. S. The impact of the COVID-19 pandemic on intercountry adoption and international commercial surrogacy. International Social Work, [s. l.], v. 63, n. 5, p. 665-670, 2020.

HAGUE CONFERENCE ON PRIVATE INTERNATIONAL LAW. A preliminary report on the issues arising from international surrogacy arrangements, drawn up by the Permanent Bureau. Preliminary Document No 10 of March 2012. The Hague: HCCH, 2012. Disponível em: https://assets.hcch.net/docs/d4ff8ecd-f747-46da-86c3-61074e9b17fe.pdf. Acesso em: 15 nov. 2020.

HARLAND, A.; LIMON, C. Recognition of parentage in surrogacy arrangements in Australia. In: GERBER, P.; O'BYRNE, K. (ed.). Surrogacy, law and human rights. London: Ashgate, 2015. p. 145-166.

HEWITSON, G. The commodified womb and neoliberal families. Review of Radical Political Economics, [s. l.], n. 46, p. 489-495, 2014.

HOEYER, K. Person, patent and property: a critique of the commodification hypothesis. BioSocieties, [s. l.], v. 2, n. 3, p. 327-348, 2007.

HORSEY, K. Fraying at the edges - UK surrogacy law in 2015. Medical Law Review, [s. l.], v. 24, n. 4, p. 608-621, 2016.

JACOBSON, H. Labor of love. New Brunswick: Rutgers University Press, 2016.

JADVA, V.; GAMBLE, N.; PROSSER, H. Cross-border and domestic surrogacy in the UK context: an exploration of practical and legal decision-making. Human Fertility, [s. l.], v. 24, n. 2, p. 93-104, 2021.

JASANOFF, S. Ordering life: law and the normalization of biotechnology. Notizie di Politeia, [s. l.], v. 17, n. 62, p. 34-50, 2001.

JASANOFF, S. Just evidence: the limits of science in the legal process. The Journal of Law, Medicine \& Ethics, [s. l.], v. 34, n. 2, p. 328-341, 2006.

JASANOFF, S. Making order: Law and science in action. In: HACKETT, E. J. et al. (ed.). The handbook of science and technology studies. 3rd ed. Cambridge: MIT Press, 2007. p. 761-786. 
JASANOFF, S. (ed.). Reframing rights: bioconstitutionalism in the genetic age. Cambridge: MIT Press, 2011.

KEYES, M. Australia. In: TRIMMINGS, K.; BEAUMONT, P. (ed.). International surrogacy arrangements: legal regulation at the international level. Oxford: Bloomsbury Publishing, 2013. p. 25-48.

KOPYTOFF, I. The cultural biography of things: commoditization as process. In: APPADURAI, A. (ed.). The social life of things: commodities in cultural perspective. Cambridge: Cambridge University Press, 1986. p. 64-91.

KOPYTOFF, I. Commoditizing kinship in America. In: TAYLOR, J. S. (ed.). Consuming motherhood. Piscataway: Rutgers University Press, 2004. p. 271-278.

KOSHY, S. Neoliberal family matter. American Literary History, [s. l.], v. 25, n. 2, p. 344380, 2013.

LATOUR, B. We have never been modern. Cambridge: Harvard University Press, 1993.

MELHUUS, M. Problems of conception: issues of law, biotechnology, individuals and kinship. New York: Berghahn Books, 2012.

MILLBANK, J. The new surrogacy parentage laws in Australia: cautious regulation or “25 Brick Walls”?. Melbourne University Law Review, [s. l.], v. 35, n. 1, p. 165-207, 2011.

ORFORD, A. Trade, human rights and the economy of sacrifice. In: ORFORD, A. (ed.). International law and its others. Cambridge: Cambridge University Press, 2006. p. 156-196.

PAYNE, J. G. Autonomy in altruistic surrogacy, conflicting kinship grammars and intentional multilineal kinship. Reproductive Biomedicine \& Society Online, [s. l.], n. 7, p. 66-75, 2018.

POTTAGE, A. The socio-legal implications of the new biotechnologies. Annual Reviews of Law and Social Sciences, [s. l.], n. 3, p. 321-344, 2007.

RADIN, M. J. From baby-selling to boilerplate: reflections on the limits of the infrastructures of the market. Osgoode Hall Law Journal, [s. l.], n. 54, p. 339, 2016.

RUDRAPPA, S. Discounted life. New York: New York University Press, 2015.

SMERDON, U. R. Birth registration and citizenship rights of surrogate babies born in India. Contemporary South Asia, [s. l.], v. 20, n. 3, p. 341-358, 2012.

SMERDON, U. R. India. In: TRIMMINGS, K.; BEAUMONT, P. (ed.). International surrogacy arrangements: legal regulation at the international level. Oxford: Bloomsbury Publishing, 2013. p. 187-218. 
SMIETANA, M. Procreative consciousness in a global market: gay men's paths to surrogacy in the USA. Reproductive Biomedicine \& Society Online, [s. l.], n. 7, p. 101-111, 2018.

SMIETANA, M.; RUDRAPPA, S.; WEIS, C. Moral frameworks of commercial surrogacy within the US, India and Russia. Sexual and Reproductive Health Matters, [s. l.], v. 29, n. 1, p. 1-17, 2021.

SMOLIN, D. Child laundering: how the intercountry adoption system legitimizes and incentivizes the practices of buying, trafficking, kidnapping, and stealing children. The Wayne Law Review, [s. l.], n. 52, p. 113-200, 2006.

SMOLIN, D. Surrogacy as the sale of children: applying lessons learned from adoption to the regulation of the surrogacy industry's global marketing of children. Pepperdine Law Review, [s. l.], n. 43, p. 265, 2015.

STARK, B. Transnational surrogacy and international human rights law. ILSA Journal of International \& Comparative Law, [s. l.], v. 18, n. 2, p. 369-386, 2011-2012.

STOROW, R. The phantom children of the republic: international surrogacy and the new illegitimacy. Journal of Gender and Social Policy and Law, [s. l.], v. 20, n. 3, p. 561-609, 2012.

STRATHERN, M. Kinship, law and the unexpected: relatives are always a surprise. Cambridge: Cambridge University Press, 2005.

THOMPSON, C. Making parents: the ontological choreography of reproductive technologies. Cambridge: MIT Press, 2005.

TOBIN, J. To prohibit or permit: what is the (human) rights response to the practice of international surrogacy? International and Comparative Law Quarterly, [s. l.], v. 63, n. 2, p. 317-352, 2014.

VAN BEERS, B. Is Europe giving in to baby markets? Reproductive tourism in Europe and the gradual erosion of existing limits to reproductive markets. Medical Law Review, [s. l.], v. 23, n. 1, p. 103-134, 2014.

VAN WICHELEN, S. Moving children through private international law: institutions and the enactment of ethics. Law \& Society Review, [s. l.], v. 53, n. 3, p. 671-705, 2019.

VORA, K. Indian transnational surrogacy and the commodification of vital energy. Subjectivity, [s. l.], v. 28, n. 1, p. 266-278, 2009.

WALDBY, C.; COOPER, M. The biopolitics of reproduction: post-fordist biotechnology and women's clinical labour. Australian Feminist Studies, [s. l.], v. 23, n. 55, p. 57-73, 2008. 
WRIGHT, A. C. et al. Narrating connection in intercountry adoption: complexities of openness in Taiwan-Australia adoptions. International Journal of Social Welfare, [s. l.], v. 30, n. 3, p. 305-315, 2021.

YNGVESSON, B. Belonging in an adopted world. Chicago: The University of Chicago Press, 2010.

Recebido: 17/11/2020 Aceito: 10/08/2021 | Received:11/17/2020 Accepted:8/10/2021 